\title{
Double-contrast computed tomography of the shoulder
}

\author{
LAWRENCE I. FINKEL, DO \\ DAVID J. BERG, DO \\ JACK L. DAVIS, DO
}

As a modality for the study of abnormalities of the shoulder, doublecontrast computed tomography (CT) is accurate, is relatively easy to perform, and requires only a low dose of radiation. The results can be extremely helpful in preoperative planning. In this study, CT images were obtained for 247 patients who had undergone routine double-contrast shoulder arthrography. Abnormalities shown on CT images included glenoid labrum attenuation and tears, glenoid fractures, loose joint bodies, intracapsular staples, intra-articular screws, adhesive capsulitis, rotator cuff tears, peritendinitis calcarea, biceps tendon tears, and capsular abnormalities. In the 41 cases in which surgical correlation was available, all of the confirmed abnormalities had been identified on double-contrast CT images. Of the patients with rotator cuff tears, $80 \%$ had other abnormalities of the shoulder, and 48\% had glenoid labrum tears. Of the patients with peritendinitis calcarea, $40 \%$ had glenoid labrum tears, and $33 \%$ had rotator cuff tears. Double-contrast CT studies of the shoulder are recommended when patients experience a decrease in range of motion, persistent shoulder pain, or signs of instability. Frequently, patients with rotator cuff tears and peritendinitis calcarea have coexisting abnormalities.

The shoulder is the most mobile joint in the body. ${ }^{1}$ When this joint becomes painful or unstable or when its motion becomes restricted, often specific supplementary diagnostic imaging or ra- diographic studies are needed to confirm or establish a diagnosis.

In both acute dislocations and chronic or recurrent anterior dislocations, a notched glenohumeral defect or compression fracture (Hill-Sachs lesion ${ }^{2}$ ) may be seen in the posterolateral portion of the humeral head. Without special radiographic views, this lesion is frequently overlooked. Various projections were developed by Didiée, ${ }^{3}$ Hermodsson, ${ }^{4}$ and Stryker, as reported by Hall and colleagues. ${ }^{5}$ The "notch view" roentgenogram (Stryker) showed Hill-Sachs lesion in $90 \%$ of patients with recurrent anterior glenohumeral dislocations confirmed at surgery. ${ }^{5}$ Although no one radiographic view is $100 \%$ accurate in showing this lesion, Danzig and colleagues ${ }^{6}$ reported that in combination, the anteroposterior view of the glenohumeral joint with the humerus in 45 degree internal rotation, the notch (Stryker) view, and the modified Didie'e view were $100 \%$ sensitive. $^{6}$

The Hill-Sachs deformity has also been associated with erosion or fracture of the anterior glenoid rim seen in dislocations of the shoulder. ${ }^{5,7}$ Bank$\mathrm{art}^{8}$ contended that the glenoid labrum on the anterior portion of the capsule was detached from the anterior aspect of the scapula on the glenoid rim by the dislocating humeral head. This, he thought, was the "essential lesion" in determining future recurrence. The labrum is often, but not always, damaged in recurrent dislocations. ${ }^{9}$ In 1950 , Townley ${ }^{10}$ described the "capsular mechanism" as "the function of the normal capsule which allows this usually lax structure to become an effective barrier against anterior projection of the humeral head in external rotation." He demonstrated that after the removal of the anterior labrum by the posterior approach, no anterior dislocation of the joint could be produced if the anterior capsule re- 
mained intact. If a pathologic condition is suspected on clinical examination, radiologic imaging of the labrum and capsule is needed for accurate documentation and for surgical planning. ${ }^{11-13}$

Historically, the labrum was evaluated by singlecontrast arthrography, double-contrast arthrography, arthrotomography, and polytomography. ${ }^{11,14-19}$ More recently, clinicians have reported doublecontrast CT to be an easy and accurate modality for the evaluation of the glenoid labrum with a relatively low radiation dose. . $^{3,20,21}$

When the results of the clinical examination suggest a rotator cuff tear, a radiologic study is warranted to confirm the tear and to exclude other pathologic conditions in the shoulder that may produce similar symptoms. ${ }^{22-25}$ In most cases in which the patient has a tear, the plain film views are either normal or nonspecific. ${ }^{17}$ Cotton and Rideout summarized the radiologic findings for patients with longstanding and chronic tears. ${ }^{26}$ These findings included a decrease in space between the humeral head and the undersurface of the acromion $(<7 \mathrm{~mm})$, cystic changes at the insertion site of the supraspinatus tendon onto the humerus, sclerosis of the greater tuberosity, prominence of the groove between the greater tuberosity and peripheral articular surface, and sclerosis and increased convexity of the undersurface of the acromion.

A suspected rotator cuff tear is the most common indication for shoulder arthrography, which was first described by Oberholzer ${ }^{27}$ in 1933 . Oberholzer used air as the contrast agent. In later arthrographic studies, iodinated material was used as a single positive-contrast medium. ${ }^{16,28-30}$ In 1977 , Ghelman and Goldman ${ }^{31}$ found that the doublecontrast arthrogram made with air and iodinated contrast medium was equally as accurate as the single-contrast study and had the added advantages of showing the width of the tear and indicating severe degenerative disease in the tendons. Subacromial bursography ${ }^{32}$ and ultrasound ${ }^{23,33}$ have also been used to image rotator cuff tears that were not visible on arthrograms.

Single and double-contrast arthrography of the shoulder have also been extremely useful in the evaluation of adhesive capsulitis, the biceps tendon, and loose joint bodies. ${ }^{14,28-29,34-35}$ Recently, double-contrast CT arthrography has been used in the evaluation of the glenoid labrum, rotator cuff, joint capsule, and articular surfaces. ${ }^{1,12-13,20-21,36-37}$ In comparison with polytomography, the technique has been found to be relatively more comfortable for the patient, easier to perform, slightly more accurate, and lower in radiation dose. ${ }^{12-13,21,38}$

\section{Material and methods}

A total of 247 double-contrast CT examinations of the shoulder were performed on 196 men and 51 women, aged 14 to 77 years. Clinical histories included a decrease in range of motion, shoulder pain, or signs of shoulder instability.

All patients had plain-film radiography of the shoulders and double-contrast arthrography. After the skin was prepared and local anesthesia was administered to the anterior aspect of the shoulder, a 22-gauge spinal needle was inserted into the glenohumeral joint under fluoroscopic control; then $2 \mathrm{~mL}$ of positive contrast medium (Conray-43) with $0.2 \mathrm{~mL}$ of $1: 1000$ epinephrine and 10 to $12 \mathrm{~mL}$ of room air was injected. After the needle was removed, passive exercise was performed. In the manner described by Goldman and Ghelman, ${ }^{14}$ internal and external rotation views were then obtained while the patient held a $2.27-\mathrm{kg}$ weight, first with the patient in an erect position and then with the patient in a supine position. Immediately afterward, the patient was taken to the CT suite. For the initial 45 patients, an Elscint 905 scanner was used; and for the remaining 202 patients, a Technicare 2060 Quantum unit was used. The patient was placed in the supine position with his or her arm in a neutral position. Computed tomography scans were taken as $5-\mathrm{mm}$ thick slices at $3-\mathrm{mm}$ increments from the acromion to the inferior aspect of the axillary recess of the joint. The area of interest was magnified, and both soft tissue and bony windows were reviewed.

In reviewing the CT results, we gave particular attention to the glenoid labrum, using diagnostic criteria similar to those previously published for $\mathrm{CT}^{12,13,21,40}$ as well as for arthrotomography of the labrum. ${ }^{11,17}$ We also evaluated the tendinous cuff, joint capsule, joint bursas, osseous structures, and surrounding soft tissues. These findings were correlated with the results of surgical (15 cases) or arthroscopic (16 cases) or both procedures performed at our institution. The remaining patients with normal and abnormal CT findings either received conservative treatment or underwent surgery at other institutions, with no follow-up by us because of our wide referral base.

\section{Results}

Optimal double-contrast CT studies (Fig 1) were obtained for 237 of our 247 patients. For the remaining patients, we thought that studies would be suboptimal because of artifact from metallic apparatus in the shoulder or because of a large amount of extravasation of air and contrast from 


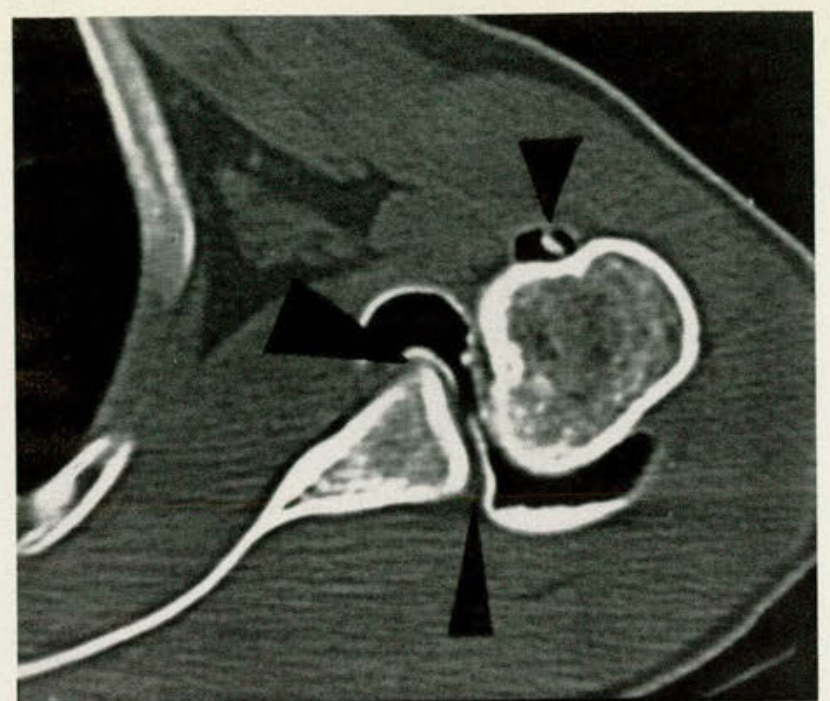

Figure 1. Double-contrast CT study of normal left shoulder. Air within the sheath outlines the tendon of the long head of the biceps ( short arrow). Anterior glenoid labrum (wide arrow). Posterior glenoid labrum (narrow arrow).

Figure 3. Tear of the anterior capsule (arrow), with periosteal stripping of glenoid and avulsion of the anterior labrum.

the shoulder joint. Of the 237 CT scans, 120 (50.6\%) appeared abnormal. Of these, $41(34 \%)$ showed complete rotator cuff tears. Except for one, which had appeared as only a partial tear on the arthrogram (Fig 2), all these tears had been seen on the conventional double-contrast arthrogram made before the CT. Fifty-nine (50\%) of the CT scans showed anterior or posterior glenoid labrum tears, of which 55 were located anteriorly (Figs 3,4 ) and ten, posteriorly. In three studies, both anterior and posterior labrum tears were present. For $55(45.8 \%)$ patients, the CT scan showed degenerative changes of the humeral head, glenoid fossa, or acromion (Fig $5)$.

For 33 patients, the CT studies showed fracture deformities of the shoulder, consisting of humeral head fractures (such as Hill-Sachs deformities), glenoid fractures (including Bankart lesions), and fractures of the acromion process (Figs 4,6-10). For four patients, the studies showed osseous loose joint bodies (Fig 8), and for one patient, two metallic staples extending into the joint capsule, migrating from previous shoulder surgery for recurrent dislocations (Figs 11,12). In another patient, a surgical screw extended through the anterior glenoid rim, resulting in loss of the labrum.

Fifteen patients had peritendinitis calcarea, which was seen on both the routine radiographs

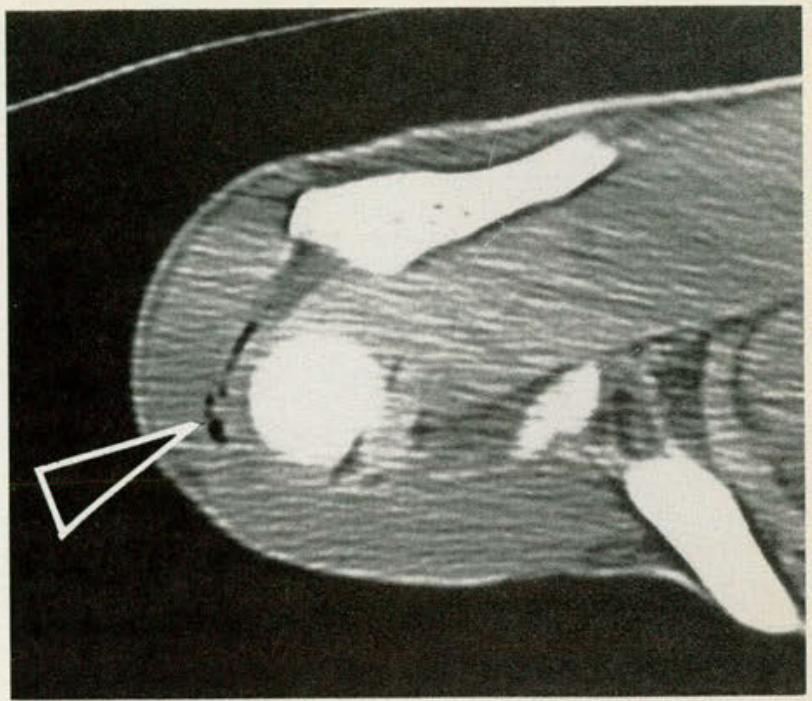

Figure 2. Air within the subacromial-subdeltoid bursa (arrow) indicates a complete rotator cuff tear. The tear was not identified on the preceding arthrogram.
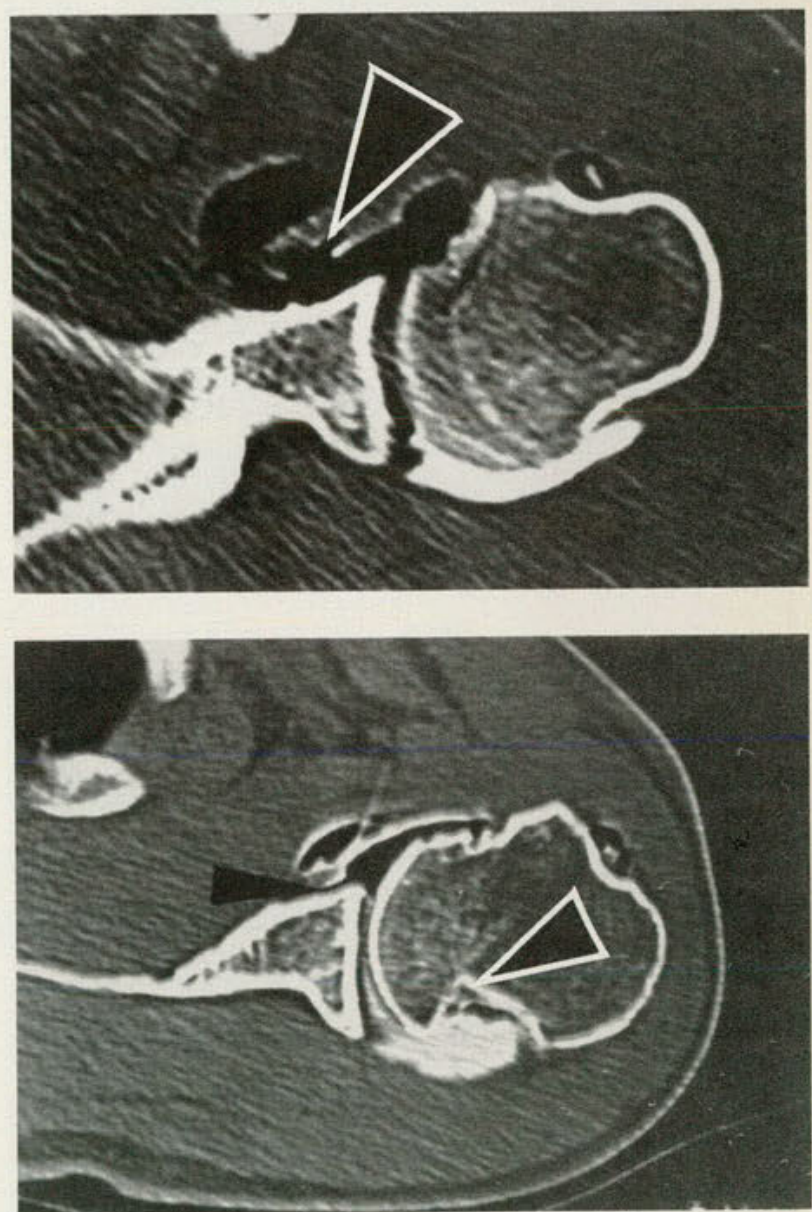

Figure 4. Large Hill-Sachs deformity of the humeral head (large arrow) in patient with history of anterior dislocation. Avulsion of anterior labrum, with partial avulsion at the anterior capsule to the glenoid (small arrow). 




Figure 5. Complete degenerative rotator cuff tear, with air in subacromial-subdeltoid bursa and degenerative cystic changes of the humeral head.



Figure 6. Avulsed fracture fragment of posterior rim of glenoid (arrow).

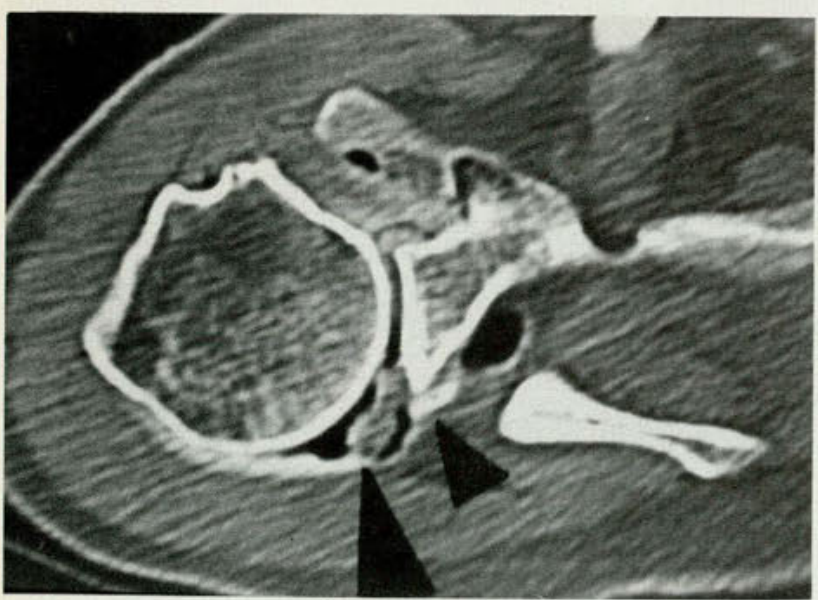

Figure 7. Avulsed fragment of posterior glenoid (small arrow), with tear of posterior labrum and fragment in posterior joint capsule (large arrow). and CT scans. However, nine $(60 \%)$ of these also had other abnormalities of the shoulder. Six (40\%) had associated glenoid fractures, and $5(33 \%)$ had rotator cuff tears. Two (13\%) had adhesive capsulitis (seen in a total of five patients in this study).

Of the 41 patients with rotator cuff tears, the CT results showed that $34(80 \%)$ had associated shoulder abnormalities and $20(48 \%)$ had glenoid labrum abnormalities, including anterior or posterior labral tears or both in 11 patients and degenerative labral thinning in 9 patients (Table). In $11(26 \%)$ of the patients with rotator cuff tears, the CT results showed osseous degenerative changes involving the acromion, glenoid labrum, or humeral head (Fig 5). Four patients had associated avulsion fractures of the glenoid labrum or acromion. Other associated abnormalities included biceps tendon ruptures ( 2 patients), peritendinitis calcarea ( 5 patients), adhesive capsulitis ( 1 patient), and loose joint bodies (3 patients).

Surgery or arthroscopy or both was done in 41 patients whose double-contrast CT results were abnormal. In 17 of these patients, rotator cuff tears were present. In 25, glenoid labrum abnormalities (tear, detachment, attenuation) were present. These abnormalities included anterior glenoid labrum tears (18 patients), posterior labrum tears (6 patients), degenerative thinning of the labrum ( 3 patients), and tears of both the anterior and posterior aspects of the labrum (4 patients). One patient had associated adhesive capsulitis. All of the labral abnormalities had been visualized on the double-contrast CT studies. Not all rotator cuff surgical procedures included arthroscopy or visualization of the glenoid labrum.

\section{Discussion}

Many possible causes exist for shoulder pain, instability, or restriction, and these have been well described in the literature. ${ }^{22,25,39-46}$ Routine radiographs may delineate osseous abnormalities and certain pathologic conditions in the soft tissue ${ }^{45}$; however, they cannot always confirm clinically suspected subtle lesions in the bone, soft tissue, or capsule. Such lesions include rotator cuff tears, glenoid labrum tears, articular abnormalities, adhesive capsulitis, biceps tendon tears, small avulsion fractures, and loose joint bodies.

Since 1938, arthrography has been used as an accurate method of detecting complete rotator tears and incomplete tears of the inferior surface of the rotator cuff. $22,27,28,30,47$ Goldman and Ghelman's technique of double-contrast arthrography is equally as accurate as single-contrast arthrography, and 



Demonstrated efficacy in a wide range of patients ${ }^{1}$ Low side-effect profile ${ }^{2 *}$ Convenient bid dosage

*Most commonly reported side effects in clinical trials include edema, headache, dizziness, asthenia, sinus bradycardia, flushing, and $1^{\circ} \mathrm{AV}$ block 


\section{Starting Dosage:}

\section{Q $90 \mathrm{mg}$ \\ $90 \mathrm{mg}$ bid* \\ Also Available: 120-mg capsules}

-Dosage must be adjusted to each patient's needs, starting with 60 to 120 $\mathrm{mg}$ twice daily.

\section{BRIEF SUMMARY}

CARDIZEM ${ }^{2}$ SR

(diltiazem hydrochloride)

Sustained Release Capsil
CONTRAINDICATIONS

CARDIZEM is contraindicated in (1) patients with sick sinus syndrome except in the presence of a functioning ventricular pacemaker, (2) patients with secondor third-degree Av block except in the presence of a functioning ventricular (4) patients who have demonstrated hypersensitivity to the $\mathrm{mm}$ Hg systolic). tients with acute myocardial infarction and pulmonary congestion documented by $x$-ray on admission.

WARNINGS

1. Cardiac Conduction. CARDIZEM prolongs AV node refractory periods without significantly prolonging sinus node recovery time, except in patients with sick sinus syndrome. This eflect may rarely result in abnormally slow heart rates (particularly in patients with sick sinus syndrome) or second-or third-degree AV block (nine of 2,111 patients or $0.43 \%$ ). Concomitant use of diltiazem with beta-blockers or digitalis may result in additive effects on cardiac conduction. A patient with Prinzmetal's angina developed periods of asystole (2 to 5 seconds) after a single dose of $60 \mathrm{mg}$ of diltiazen.

2. Congestive Heart Failure. Although diltiazem has a negative inotropic effect in isolated animal tissue preparations, hemodynamic studies in humans with normal ventricular function have not shown a reduction in cardiac inder no consistent negative effects on contractility $(d p / d t)$. An acute study of ord diltiazem in patients with impaired ventricular function (ejection fraction $24 \% \div 6 \%$ ) showed improvement in indices of ventricular function withou significant decrease in contractile function (dp/dt). Experience with the use of CARDizEM (ditiazem hydrochloride) in combination with beta-blockers in patients with impaired ventricular function is limited. Caution should be exercised when using this combination.

3. Hypotension. Decreases in blood pressure associated with CARDIZEM therapy may occasionally result in symptomatic hypotension.

4. Acute Hepatic Injury. Mild elevations of transaminases with and without concomitant elevation in alkaline phosphatase and bilirubin have been observed in clinical studies. Such elevations were usually transient and frequently resolved even with continued diltiazem treatment. In rare in stances, significant elevations in enzymes such as alkaline phosphatase, $\mathrm{LOH}, \mathrm{SGO}$, SGPF, and other phenomena consistent with acute hepatic injury have been noted. These reactions tended to occur early after therapy initiation (1 to 8 weeks) and have been reversible upon discontinuation of drug therapy. The relationship to CARDIZEM is uncertain in some cases, but probable in some. (SEe PRECAUTIONS

\section{PRECAUTIONS}

General. CARDIZEM (diltiazem hydrochloride) is extensively metabolized by the liver and excreted by the kidneys and in bile. As with any drug given over prolonged periods, laboratory parameters should be monitored at regular intervals. The drug should be used with caution in patients with impaired renal or hepatic function. In subacute and chronic dog and rat studies designed to produce toxicity, high doses of diltiazem were associated with hepatic damage In special subacute hepatic studies, oral doses of $125 \mathrm{mg} / \mathrm{kg}$ and higher in rats were associated with histological changes in the liver which were reversible when the drug was discontinued. In dogs, doses of $20 \mathrm{mg} / \mathrm{kg}$ were also associated with hepatic changes; however, these changes were reversible with continued dosing Dermatological events (see ADVERSE REACTIONS section) may be transient and may disappear despite continued use of CARDIZEM. However skin eruntions progressing to erythema multiforme and/or exfoliative dermatitis have also been infrequently reported. Should a dermatologic reaction persist, the drug should be discontinued.

Orug Interaction. Due to the potential for additive effects, caution and carefol titration are warranted in patients receiving CARDIZEM concomitantly with any agents known to affect cardiac contractility and/or conduction. (See WARNINGS) Pharmacologic studies indicate that there may be additive effects in prolonging AV conduction when using beta-blockers or digitalis concomitantly with
CARDIZEM. (SEe WARNINGS.)

As with all drugs, care should be exercised when treating patients with multiple medications. CARDIZEM undergoes biotransformation by cytochrome which follow the same oxidase. Coadministration of CARDIZEM with other agents inhibition of metabolism. Dosages of similarly metay result in the competitive those of low therapeutic ratio or in patients with renal and/or hepatic impairment.

\section{CARDIZEMSSR (diltiazem HCl) sustained release capsules}
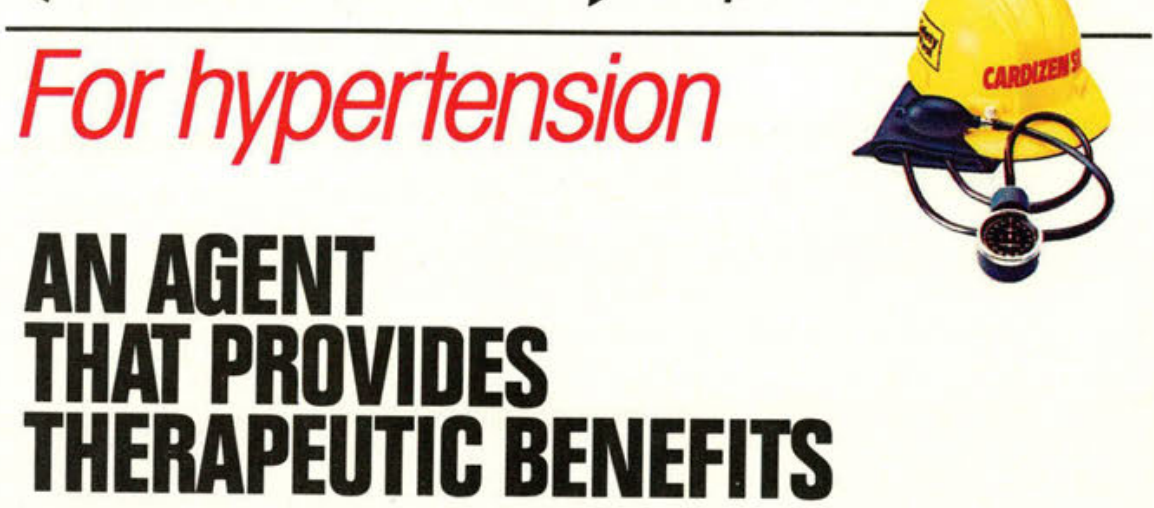

may require adjustment when starting or stopping concomitantly administered

Beta-blockers: Controlled and uncontrolled domestic studies suggest that concomitant use of CARDIZEM and beta-blockers or digitalis is usually well olerated, but available data are not sufficient to predict the effects of concomitant treatment in patients with left ventricular dysfunction or cardiac conduction

Administration of CARDIZEM (diltiazem hydrochloride) concomitantly with propranolol in five normal volunteers resulted in increased propranolol levels in all subjects and bioavailability of propranolol was increased approximately $50 \%$. If combination therapy is initiated or withdrawn in conjunction with propranolo. an adjustment in the propranolol dose may be warranted. (See WARNINGS.)

Cimetidine: A study in six healthy volunteers has shown a significant increase in peak diltiazem plasma levels $(58 \%)$ and area-under-the-curve $(53 \%)$ after a 1-week course of cimetidine at $1,200 \mathrm{mg}$ per day and diltiazem $60 \mathrm{mg}$ per day. Ranitidine produced smaller, nonsignificant increases. The effect may be mediated by cimetidine's known inhibition of hepatic cytochrome P-450, the enzyme system probably responsible for the first-pass metabolism of diltiazem. Patients currently receiving diltiazem therapy should be carefully monitored for a change
in pharmacological effect when initiating and discontinuing therapy with cimetidine. An adjustment in the ditiazem dose may be warranted.

Digitalis: Administration of CARDIZEM with digoxin in 24 healthy male subjects increased plasma digoxin concentrations approximately $20 \%$. Another investigator found no increase in digoxin levels in 12 patients with corona artery disease. Since there have been conflicting results regarding the effect digoxin levels, it is recommended that digoxin levels be monitored when initiat ing. adjusting, and discontinuing CARDIZEM therapy to avoid possible overunder-digitalization. (See WARNINGS

Anesthetics: The depression of cardiac contractility. conductivity, and automaticity as well as the vascular dilation associated with anesthetics may be men used concomitantly, anesthetics and calcium blockers should be titrated carefully.

Carcinogenesis, Mutagenesis, Impairment of Fertility. A 24-month study in rats and a 21 -month study in mice showed no evidence of carcinogenicity. There was also no mutagenic response in in vitro bacterial tests. NNo intrinsic effect on fertility was observed in rats.

Pregnancy. Category C. Reproduction studies have been conducted in mice, rats, and rabbits. Administration of doses ranging from five to ten times greater lon a mg/kg basis) than the daily recommended therapeutic dose has resulted in embryo and cetal iethality. These doses, in some studies, have been reported to cause skeletal abnormalties. In the perinatal postnatal studies, there was some reduction in early individual pup weights and survival rates. There was an Chere ar Tapoize CARDIZEM in pregnant women only if the potential benefit justifies the potentia

Nursing Mothers. Diltiazem is excreted in human milk. One report suggests that concentrations in breast milk may approximate serum levels. If use of CARDIZEM is deemed essential, an alternative method of infant feeding should be instituted

Pediatric Use. Safety and effectiveness in children have not been established. ADVERSE REACTIONS

Serious adverse reactions have been rare in studies carried out to date, but it should be recognized that patients with impaired ventricular function and cardiac The adverse events described below reen excluded from these studies.

the adverse events described below represent events observed in clinical studies Capsules as well as tents receving either CAnDizeN Tablets or CARDIZEM SR Capsules as well as experiences observed in studies of angina and duning marketa bates in placebo patinn show for com parison. Less common events are listed by body system, these include any adverse reactions seen in angina studies that were not diminess $(6 \%$ ) common adverse events were edema $(9 \%)$, headache $18 \%$, imess The most 0 in edema and perhaps bradycardia and dizaness were dose related The most compon events observed in cinical studies (over 2,100 patients) of CARDa patients and hypertensive patients receiving CAROIZEM Tablets or CAndizen SR Capsules were (re, greater than $1 \%$ ) edema $(5.4 \%)$, headache $4.5 \%$ ), diziness $(3.4 \%)$, asthenia $(2.8 \%$, first-degree AV block (1.8\%), flushing $1.7 \%)$, nausea $(1.6 \%)$, bradycardia $(1.5 \%)$, and rash (1.5\%).

\begin{tabular}{|l|c|c|}
\hline \multicolumn{3}{|c|}{$\begin{array}{c}\text { DOUBLE BLIND PLACEBO CONTROLLED } \\
\text { HYPERTENSION TRIALS }\end{array}$} \\
\hline & $\begin{array}{c}\text { Diltiazem } \\
\text { N=315 } \\
\text { \# pts }(\%)\end{array}$ & $\begin{array}{c}\text { Placebo } \\
\text { Adverse } \\
\text { \# pts }(\%)\end{array}$ \\
\hline headache & $38(12 \%)$ & $17(8 \%)$ \\
\hline AV block first degree & $24(7.6 \%)$ & $4(1.9 \%)$ \\
\hline dizziness & $22(7 \%)$ & $6(2.8 \%)$ \\
\hline edema & $19(6 \%)$ & $2(0.9 \%)$ \\
\hline bradycardia & $19(6 \%)$ & $3(1.4 \%)$ \\
\hline ECG abnormality & $13(4.1 \%)$ & $3(1.4 \%)$ \\
\hline asthenia & $10(3.2 \%)$ & $1(0.5 \%)$ \\
\hline constipation & $5(1.6 \%)$ & $2(0.9 \%)$ \\
\hline dyspepsia & $4(1.3 \%)$ & $1(0.5 \%)$ \\
\hline nausea & $4(1.3 \%)$ & $2(0.9 \%)$ \\
\hline palpitations & $4(1.3 \%)$ & $2(0.9 \%)$ \\
\hline polyuria & $4(1.3 \%)$ & $2(0.9 \%)$ \\
\hline somnolence & $4(1.3 \%)$ & - \\
\hline alk phos increase & $3(1 \%)$ & $1(0.5 \%)$ \\
\hline hypotension & $3(1 \%)$ & $1(0.5 \%)$ \\
\hline insomnia & $3(1 \%)$ & $1(0.5 \%)$ \\
\hline rash & $3(1 \%)$ & $1(0.5 \%)$ \\
\hline AV block second degree & $2(0.6 \%)$ & - \\
\hline
\end{tabular}

In addition, the following events were reported infrenuently (less than $1 \%$ ) or have been observed in angina trials. In many cases, the relation to drug is

Cardiovascular: Angina, arrthythmia, bundle branch block, tachycardia, ventricular extrasystoles, congestive heart failure, syncope. Nervous System: Amnesia, depression, gait abnormality, hallucinations, nervousness, paresthesia, personality change, tinnitus, tremor Anorevia, diarrhea, dysgeusia, mild elevations of SGOT, SGPT, and LDH (see hepatic warnings), vomiting, weight increase, thirst.

Dermatological: Petechiae, pruritus, photosensitivity, urticaria

Other: Amblyopia, CPK increase, dyspnea, epistaxis, eye irritation, hyperglycemia, sexual difficulties, nasal congestion, nocturia, osteoarticular pain, impotence, dry mouth.

The following postmarketing events have been reported infrequently in patients receiving CARDIZEM. alopecia, gingival hyperplasia, erythema multiforme, and CARDIZEM therapy cannot yet be established. Issued 1/89

References: 1. Pool PE, Seagren SC, Salel AF: $A m \mathrm{~J}$ Cardiol 1985;56:86H-91H. 2. Frishman WH, Zawada ET Jr, Smith LK, et al: Am J Cardiol 1987;59:615-623.

Another patient benefit product from

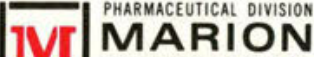
LABORATORIES, INC.
CSRAB001

1592E9 




Figure 8. Central fracture of glenoid (narrow arrow). Torn anterior labrum, with associated loose joint body (wide arrow).

it provides more information about the width of the tear and the quality of the remaining tissue. ${ }^{14,31}$ Arthrography cannot show intrasubstance or bursal side tears. ${ }^{35}$ Subacromial bursography has been used as a complementary procedure to shoulder arthrography for detecting incomplete tears of the superior surface of the rotator cuff. ${ }^{32}$

In 1984, Crass and associates ${ }^{23}$ used ultrasound to detect complete as well as incomplete tears of the rotator cuff. However, ultrasound cannot show associated soft tissue and skeletal abnormalities. Double-contrast CT of the shoulder has the advantage of being able to detect complete and incomplete rotator cuff tears and, in addition, to detect associated internal derangements. ${ }^{12,13,20,21,37,48}$ Beltran and colleagues ${ }^{37}$ thought that direct sagittal CT arthrography was preferable to axial CT scanning. However, they were of the opinion that CT arthrography should be combined with axial CT, which is more sensitive to glenoid labrum tears.

Of the 41 patients in our series with rotator cuff tears, $34(80 \%)$ had other osseous or soft tissue abnormalities of the shoulder; $20(48 \%)$ had glenoid labrum abnormalities, the majority of which were tears of the anterior or posterior aspect (or both) of the labrum, and $11(26 \%)$ had osseous degenerative changes of the shoulder (Table). Also seen were avulsion fractures, biceps tendon ruptures, peritendinitis calcarea, adhesive capsulitis, and loose joint bodies.

Rafii and associates ${ }^{21}$ reported that $100 \%$ of their patients with rotator cuff tears had irregularities and attenuation of the glenoid labrum. They also reported labral tears, enlarged subscapsularis bursas, stripped posterior capsules, and osteochondral fractures of the glenoid in these patients. Reeves ${ }^{16}$

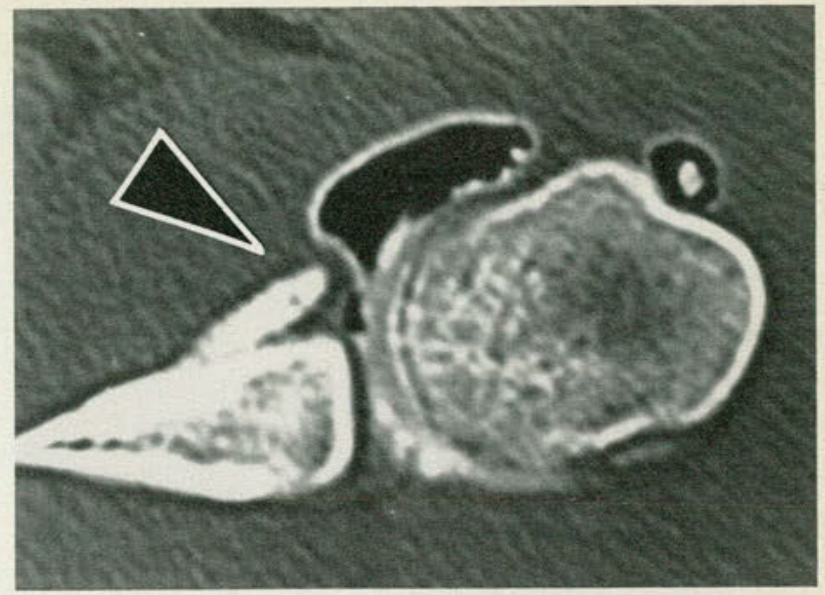

Figure 9. Avulsed fragment of anterior glenoid (arrow).

reported that rotator cuff tears coexisted with other pathologic changes in patients with shoulder instability. While conventional arthrography can accurately show rotator cuff tears, double-contrast CT can be extremely helpful in the preoperative assessment of any of the associated internal derangements. In one patient in our series, doublecontrast CT showed a complete rotator cuff tear with a small amount of air in the subacromial and subdeltoid bursa; in the preceding arthrogram, the abnormality had been seen only as a partial tear (Fig 11). We assume that the tear in the rotator cuff was very small and that the air did not work its way entirely through it during the conventional arthrogram but did so by the time the CT was completed.

\begin{tabular}{|lc|}
\hline \multicolumn{2}{|c|}{$\begin{array}{c}\text { Table } \\
\text { Association of Rotator Cuff Tears } \\
\text { With Other Shoulder Abnormalities }\end{array}$} \\
\hline \multicolumn{2}{|c|}{ No. of cases } \\
\hline Shoulder abnormality & 41 \\
\hline Rotator cuff tears & 34 \\
Associated abnormalities* & 20 \\
Glenoid labrum abnormalities & 11 \\
$\quad$ Anterior or posterior tears & 9 \\
$\quad$ (or both) & 11 \\
Degenerative thinning & 4 \\
Osseous degenerative changes & 2 \\
Avulsion fractures & 5 \\
Biceps tendon ruptures & 1 \\
Peritendinitis calcarea & 3 \\
Adhesive capsulitis & \\
Loose joint bodies & 7 \\
No associated abnormalities & \\
\hline * Patients may have more than one abnormality. & \\
&
\end{tabular}


Figure 10. Avulsion fracture of anterior rim of glenoid, with loss of the anterior labrum (arrow).

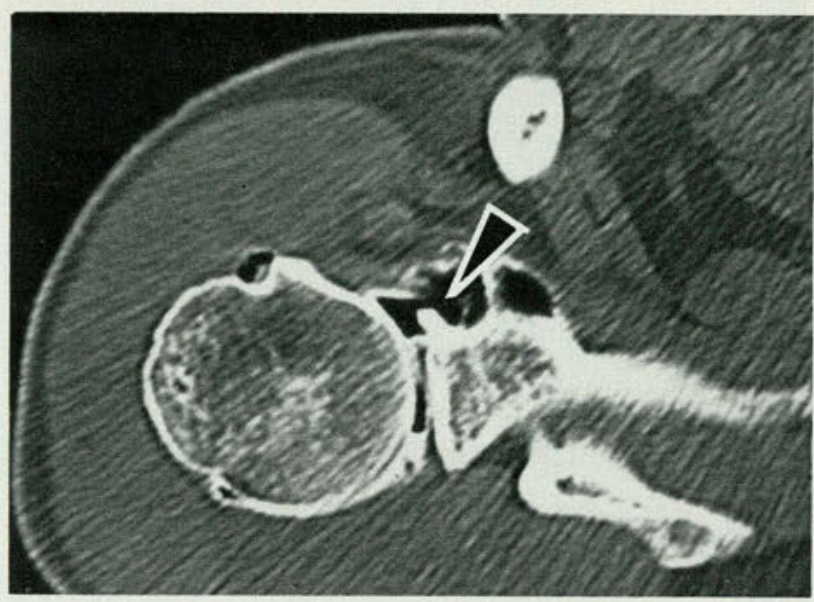

Figure 11. Metallic staple extending through the joint capsule (arrow). Note also the loss of the anterior glenoid labrum.



Figure 12. Metallic surgical screw extending through the anterior rim of glenoid with loss of anterior labrum (arrow).

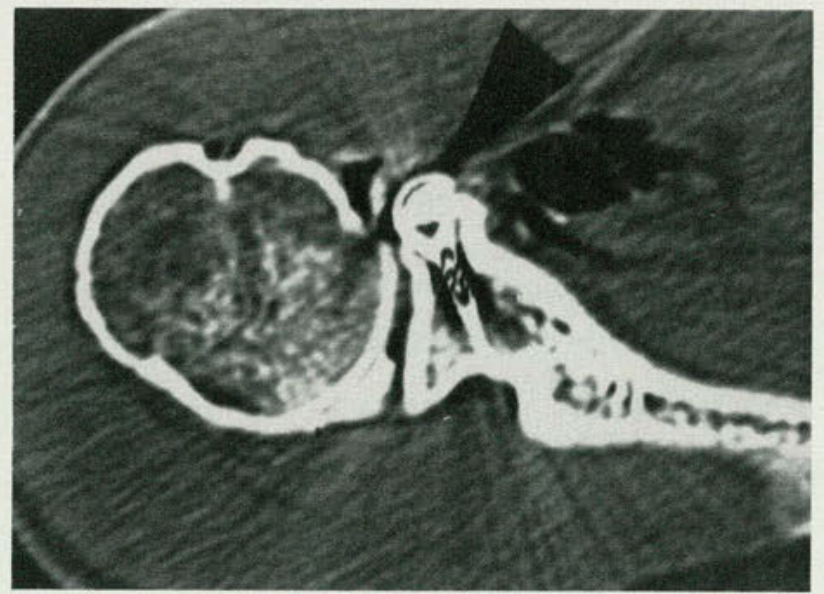


The normal glenoid labrum deepens and increases the surface area of the shallow bony glenoid for the much larger humeral head. ${ }^{17}$ Most authors have thought that the labrum is intimately involved with the capsular mechanism and contributes to the stability of this very mobile shoulder joint. ${ }^{9,10,49}$ In the elevation and rotation of the arm, the capsule-labrum junction is normally the buffer in the anterior glide of the humeral head. ${ }^{9,10}$ Dislocation can be caused by a direct blow to the shoul eeder, by force transmitted from the hand or elbow, or by overpowering external rotation or hyperextension. ${ }^{10}$ The injury to the shoulder usually occurs with the shoulder in external rotation; in this position, the capsule is taut and the humeral head is abutting against it; there is less leeway for further displacement of the humeral head unless there is a disruption of the capsule. ${ }^{10}$

Reeves found the weakest point of the anterior capsule to be at the attachment of the glenoid labrum. ${ }^{50}$ McGlynn and associates ${ }^{15}$ confirmed this. In dislocations of the shoulder, isolated or coexisting traumatic damages may include tears in the labrum, stretching and stripping of the joint capsule off the bony glenoid (Fig 3); tears in the periosteum of the scapular neck; tears in the rotator cuff; fractures in the margin of the glenoid (Figs 6,7,9, 10 ), enlargement of the subscapularis bursas and compression fractures of the humeral head (HillSachs) (Fig 4). ${ }^{6,12,51}$

Since the damage caused by labral or capsular tears may be difficult to assess by clinical examination, radiologic imaging of the labrum and capsule are important to show the extent of the pathologic condition and to aid in the planning of surgery. In single-contrast arthrography, overlying contrast material often obscures the labrum. ${ }^{11,28}$ In double-contrast arthrography, ${ }^{11,14}$ pooling of contrast material may cause suboptimal delineation of the labrum. This problem may be solved by polytomography, but this method is time-consuming and sometimes technically difficult. ${ }^{17}$ In addition, the radiation dose for polytomography is up to ten times that for CT. ${ }^{38}$

Double-contrast CT has been shown to be an accurate and relatively easy method to use in the evaluation of the shoulder joint capsule and glenoid labrum. ${ }^{12,13,20,21}$

Lower and $\mathrm{McNi} \mathrm{Sh}^{36}$ reported two cases in which CT was used in determining intra-articular penetration of surgical screws. We report one case in which the patient was found to have a screw extending through the anterior glenoid (Fig 12) and another in which the patient was found to have two metallic staples completely detached from bony structures. One staple was located in the acromial humeral joint space, and the second was partially penetrating the subscapularis capsular recess (Fig 11).

Prior to our study, only one case had been reported in which osseous loose joint bodies in the shoulder had been detected by $\mathrm{CT}^{52}$ We report four such cases (Fig 8).

Computed tomography has proved to be an excellent modality for use in the evaluation of glenoid and humeral head changes and fractures. ${ }^{12,20,21,48}$ Its usefulness is well documented in our series.

Peritendinitis calcarea has been reported in up to $45 \%$ of the patients with painful shoulders. ${ }^{53,54}$ This abnormality may coexist with other lesions. Kernwein and associates ${ }^{29}$ point out that a calcified tendon is a diseased tendon and that a diseased tendon may rupture. These authors report that of 12 patients whose arthrograms showed calcium in the subacromial tissue, $9(75 \%)$ also had rotator cuff tears.

To our knowledge, the association of peritendinitis calcarea with CT-diagnosed internal derangement has not been mentioned in the literature. In our study, $40 \%$ of the patients with peritendinitis calcarea had glenoid labrum tears, and one half of these had glenoid fractures. Approximately 33\% of the patients with peritendinitis calcarea; had rotator cuff tears; and $7.5 \%$, adhesive capsulitis. This high coincidence of glenoid labrum tears and rotator cuff tears suggests that in evaluating cases of peritendinitis calcarea, it is useful to follow up a double-contrast arthrogram with a CT study, which will contribute important specific information.

1. Gray H: Gray's Anatomy of the Human Body, ed 37, Warwick R, Williams PL, Dyson M, et al (eds). New York, Churchill Livingstone, 1989, p 502 .

2. Hill HA, Sachs MD: The grooved defect of the humeral head: A frequently unrecognized complication of dislocations of the shoulder joint. Radiology 1940;35:690-700.

3. Didiée J: Le radiodiagnostic dans la luxation récidivante de lépaule. $J$ Radiol Electrol 1930;14:209-218

4. Hermodsson I: Roentgenologischen studien uber die tramatischen und habituellen schultergelenk-verrentkungen nach vorn und nach unten. Acta Radiol 1934;20:

5. Hall RH, Issac F, Booth CR: Dislocations of the shoulder with special reference to accompanying small fractures. J Bone Joint Surg Am 1959;41A:489-493.

6. Danzig LA, Greenway G, Resnick D: The Hill-Sachs lesion: An experimental study. Am J Sports Med 1980;8:328-332.

7. Bost FC, Inman VT: The pathological changes in recurrent dislocation of the shoulder: A report on Bankart's operative procedure. $J$ Bone Joint Surg 1942;24:595-613. 
8. Bankart ASB: Recurrent or habitual dislocation of the shoulder-joint Br Med J 1923;2:1132-1133.

9. Moseley HF, O..vergaard B: The anterior capsular mechanism in recurrent anterior dislocation of the shoulder. J Bone Joint Surg Br 1962;44B:913-927.

10. Townley CO: The capsular mechanism in recurrent dislocation of the shoulder. J Bone Joint Surg Am 1950;32-A:370-380.

11. Braunstein EM, O'Connor G: Double-contrast arthrotomography of the shoulder. J Bone Joint Surg Am 1982;64-A:192-195.

12. Shuman WP, Kilcoyne RF, Matsen FA, et al: Double-contrast com puted tomography of the glenoid labrum. AJR 1983;141:581-584.

13. Haynor DR, Shuman WP: Double contrast CT arthrography of the glenoid labrum and shoulder girdle. Radiographics 1984;4:411-421.

14. Goldman AB, Ghelman B: The double-contrast shoulder arthrogram: A review of 158 studies. Radiology 1978;127:655-663.

15. McGlynn FJ, El-Khoury G, Albright JP: Arthrotomography of the glenoid labrum in shoulder instability. J Bone Joint Surg A m 1982;64A:506-518.

16. Reeves B: Arthrography of the shoulder. J Bone Joint Surg Br 1966;48. B:424-435.

17. El-Khoury GY, Albright JP, Abu Yousef MM, et al: Arthrotomography of the glenoid labrum. Radiology 1979;131:333-337.

18. Kummel BM: Arthrography in anterior capsule derangements of the shoulder. Clin Orthop 1972;83:170-176.

19. Mink JH, Richardson A, Grant TT: Evaluation of glenoid labrum by double contrast shoulder arthrography. AJR 1979;133:883-887.

20. Danzig L, Resnick D, Greenwary G: Evaluation of unstable shoulders by computed tomography: A preliminary study. Am J Sports Med 1982;10:138-141.

21. Rafii M, Firooznia H, Golimbu C, et al: CT arthrography of capsular structures of the shoulder. AJR 1986;146:361-367.

22. Nixon JE, DiStefano V: Ruptures of the rotator cuff. Orthop Clin North Am 1975;6:423-447.

23. Crass JR, Craig EV, Thompson RC, et al: Ultrasonography of the rotator cuff: Surgical correlation. J Clin Ultrasound 1984;12:487-492

24. Post M, Silver R, Singh M: Rotator cuff tear: Diagnosis and treatment. Clin Orthop 1983;173:78-91.

25. Cofield RH: Rotator cuff disease of the shoulder. J Bone Joint Surg Am 1985;67-A:974-979.

26. Cotton RF, Rideout DF: Tears of the humeral rotator cuff: A radiological and pathological necropsy survey. J Bone Joint Surg Br 1964;46B:314-328.

27. Oberholzer J: Die Arthropneumoradiographic bie habitueller Schulterluxation. Rontgen-Praxis 1933:5:589-590.

28. Killoran PJ, Marcove RC, Freiberger RH: Shoulder arthrography. AJR 1968;103:658-668.

29. Kernwein GA, Rosenberg B, Sneed WR Jr: Arthrographic studies of the shoulder joint. $J$ Bone Joint Surg Am 1957;39-A:1267-1279.

30. Neviaser JS: Rupture of the rotator cuff. Clin Orthop 1954;3:92.

31. Ghelman B, Goldman AB: The double contrast shoulder, arthrogram: Evaluation of rotary cuff tears. Radiology 1977;124:251-254.

32. Lie S, Mast WA: Subacromial bursography: Technique and clinica application. Radiology 1982;144:626-630.

33. Bretzke CA, Crass JR, Craig CV, et al: Ultrasonography of the rotator cuff: Normal and pathological anatomy. Invest Radiol 1985;20:311 315.
34. Neviaser JS: Arthrography of the shoulder joint: Study of the findings in adhesive capsulitis of the shoulder. J Bone Joint Surg Am 1962;44. A(7):1321-1330.

35. Goldman AB: Shoulder Arthrography. Boston, Little, Brown \& Co, 1982

36. Lower RF, McNiesh LM, Callaghan JJ: Computed tomographic documentation of intra-articular penetration of a screw after operations on the shoulder: A report of two cases. J Bone Joint Surg Am 1985;67-A:1120. 1122 .

37. Beltran J, Gray LA, Bools JC, et al: Rotator cuff lesions of the shoulder: Evaluation by direct sagittal CT arthrography. Radiology 1986;160:161-165.

38. Baird RA, Schobert WE, Pais MJ, et al: Radiographic identification of loose bodies in the traumatized hip joint. Radiology 1982;145:661665 .

39. Bateman JE: The Shoulder and Neck, ed 2. Philadelphia, Saunders, 1978, pp 47-116.

40. Cone RO, Resnick D: Traumatic disorders of the shoulder. JAMA 1984;252:540-543.

41. Rothman RH, Marvel JP Jr, Heppenstall RB: Recurrent anterior dislocation of the shoulder. Orthop Clin North Am 1975;6:415-423.

42. Ravlov H, Freiberger RH: Fractures and dislocations about the shoulder: Semin Roentgenol 1978;13:85-96.

43. Norwood LA, Terry GC: Shoulder posterior subluxation. Am J Sports Med 1984;12:25-30.

44. Arndt JH, Sears AD: Posterior dislocation of the shoulder. AJR 1965;94:639-645.

45. Neviaser RJ: Painful conditions affecting the shoulder. Clin Orthop 1983;173 (March):63-69

46. Neer CS II: Impingement lesions. Clin Orthop 1983;173 (March):70 77.

47. Petersson CJ, Redlund-Johnell I: Joint space in normal gleno-hu meral radiographs. Acta Orthop Scand 1983;54:274-276.

48. Kinnard P, Tricoire JL, Levesque RY, et al: Assessment of the unstable shoulder by computed arthrography: A preliminary report. Am $J$ Sports Med 1983;11:157-259.

49. Rowe CR, Zarins B: Recurrent transient subluxatin of the shoulder. J Bone Joint Surg Am 1981;63-A:863-872.

50. Reeves B: Experiments on the tensile strength of the anterior capsular structures of the shoulder in man. J Bone Joint Surg Br 1968;50-B:858 865.

51. Rowe CR, Patel D, Southmayd WW: The Bankart procedure: A longterm end-result study. J Bone Joint Surg Am 1978;60-A:12-16.

52. Gould R, Rosenfield AT, Friedlaender GE: Loose body within the glenohumeral joint in recurrent anterior dislocation: CT demonstration. J Comput Assist Tomogr 1985;9:404-406.

53. Caldwell, GA, Unkauf BM: Results of treatment of subacromial bursitis in 340 cases. Ann Surg 1950;132:432.

54. Young BR: Roentgen treatment of bursitis of the shoulder. AJR 1946;56:626.

From the department of medical imaging, Phoenix General Hospital, Phoenix.

Reprint requests to Dr Finkel, 4110 N 19th Ave, Phoenix, 85015 